\title{
Major Salivary Gland Carcinoma ex Pleomorphic Adenoma
}

National Cancer Institute

\section{Source}

National Cancer Institute. Major Salivary Gland Carcinoma ex Pleomorphic Adenoma. NCI

Thesaurus. Code C5975.

A carcinoma that arises from a pleomorphic adenoma in the major salivary glands. It usually originates in the parotid gland. Patients usually present with a history of a longstanding tumor mass which grew rapidly in the past few months. Patients with noninvasive or minimally invasive carcinoma have an excellent prognosis. In cases where there is invasion of the surrounding tissues, the clinical course is aggressive. 